\title{
Jnḩaltsverzeichnif́.
}

\section{A. zeidgsgefeşe.}

Gette

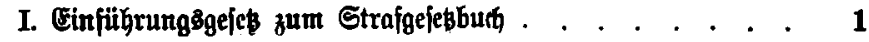

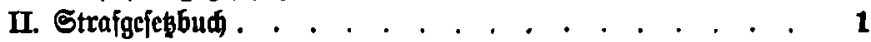

III. Einjührungggeclek zur Strafprocckorbnung . . . . . . 136

IV. Strafprocéforbnung . . . . . . . . . . . . . . 136

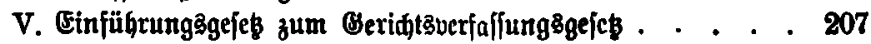

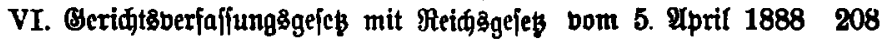

VII. Eoncursorbnung . . . . . . . . . . . . . . . . . 211

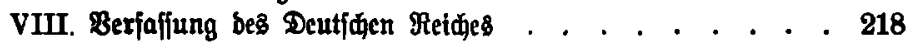

IX. Sefeß bom 12. October 1867, betr. bie Erghebung einer $\mathfrak{a b}=$ gabe bon $\mathrm{Sal}_{\mathrm{z}}$. . . . . . . . . . . . . . 218

X. Oefę bom 4. Julli 1868, betr. bie pribatredtlide Stellung ber Erwerbs: und खsirthjdaftsgenofienjiaften . . . . 219

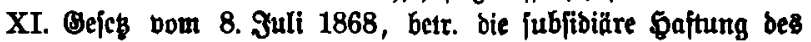
Brennereiunterneğmers u. f. w. . . . . . . . . . 219

XII. Befȩ́ bom 7. 2(pril 1869, betr. Maßjregdin gegen Die Stinberpef́t 220

XIII. Gejek vom 10. Suni 1869, betr. die \$Bedfieliftempeliteuer . 220

XIV. Bcieł vom 26. Suni 1869, betr. bic Bejteuerung bes Buđerg 221

XV. Bewerbeorbnung vom 21. Suni 1869 mit Gejeß vom 17. Juli

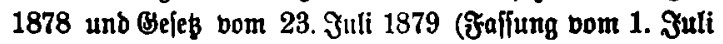
1883) . . . . . . . . . . . . . . . . . 222

XVI. Bereinszollgelę bom 1. Jufi 1869 . . . . . . . . 228

XVII. Befeß bour 11. Suni 1870, betr. bns urrgcberredt an Sdurift= werlen $\mathfrak{u}$. f. w. . . . . . . . . . . . . . . 234

XVIII. Bejęs vom 28. October 1871 übcr das ßoftrejen bes Deutjien Reides . . . . . . . . . . . . . . . . . 238

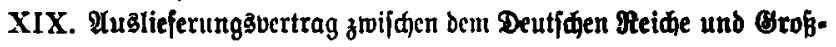
britannien bom 14. $\mathbb{M a i} 1872$. . . . . . . . . 239

XX. Gejet vom 31. Mlai 1872 wegen Erbebung ber Praufteuer. 240

XXI. Militär=Strafgefę̧buch vom 20. Эuni 1872 . . . . . . 241 


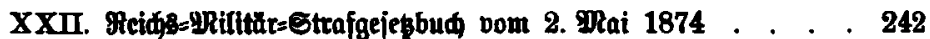

XXIII. ßrepgelés vom 7. פai 1874 . . . . . . . . . . . . . 242

XXIV. Sefes bom 30. Robember 1874, betr. ben Marlenidub , 245

XXV. Geję bom 6. Fiebruar 1875 über bie \$eurlunbung des \$ers= jonenftandes . . . . . . . . . . . . . . . 247

XXVI. Befę bou 9. Sanuar 1876, betr. bas Urheberredt an 2 serten ber bilbenten Münfte . . . . . . . . . . . . 249

XXVII. Gejeß bom 10. Samuar 1876, betr. ben Squł ber Photo= graphien . . . . . . . . . . . . . . . . 250

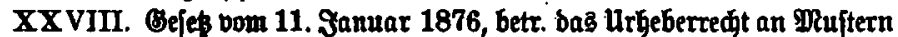
und Mpobeller . . . . . . . . . . . . . . . 251

XXIX. ßatentgefes vom 25. Wai 1877 . . . . . . . . . . 252

XXX. Bejeßs bom 21. Mai 1878, betr. Burviberbandlungen gegen

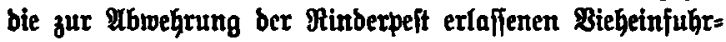
berbote . . . . . . . . . . . . . . . . . 252

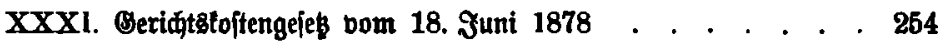

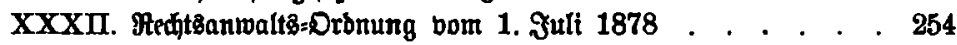

XXXIII. Bcies bom 3. Suli 1878, betr. ben Spielfartenftempel . . 254

XXXIV. Befeł vom 21. Dctober 1878, betr. Die gemeingcfährliđen $B_{e-}$ jtrebungen bex Socialdemotratie mit Beję bom 31. Mai

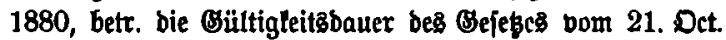
1878

XXXV. Bejeß bom 14. Mai 1879, betr. ben Berfehr mit Mahrung $8=$ mitteln . . . . . . . . . . . . . . . . . 257

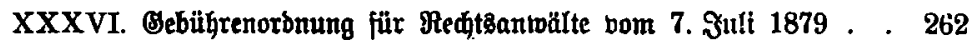

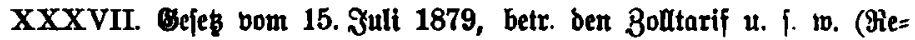
baction" bom 24. Mlat 1885) . . . . . . . . . . . . . 263

XXXVIII. Befef bom 16. Juli 1879, betr. bic Befteterung bes Sabats

XXXIX. Befeł bom 20. Suli 1879, betr. bie Statiftil bęి æaaren= vertegrs u. f. w. . . . . . . . . . . . . . : 265

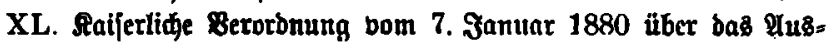
weiden ber Sdiffe . . . . . . . . . . . . . . 265

XLI. Seieb vom 24. Mai 1880, betr. den $\mathfrak{B u d e r ~ . ~ . ~ . ~ . ~ . ~} 265$

XLII, Jefę vom 23. Suni 1880, betr. Abwegr und unterbrïdung . bon ßichjeuden . . . . . . . . . . . . . . . 266

XLIII. Betidtstoftengefes in ber §̧affung vom 29. Suni 1881 . . 267

XLIV. Befeß vom 1. Juli 1881, betr. bie Erbebung von Fieids: ftempelabgaben mit Befes vom 29. Drai 1885 . . . . 267

XLV. Befes bom 17. Jult 1881, betr. bie Beftrafung von Buwider:

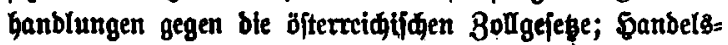
vertrag zrvifjen Deutiflanb und Defterreid]=üngarn bom 23. Mai 1881 
XLVI. Befés bom 15. Suni 1883, betr. Die Atantenberiiferung ber Orrbeiter . . . . . . . . . . . . . . . . .

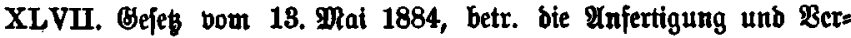
zollung bon günofölzern . . . . . . . . . . . 270

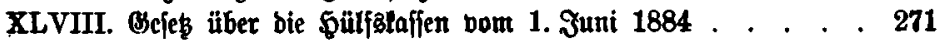

XIIX. Bejes bom 9. Suni 1884 gegen ben verbredierijden unb ge= meingefährlidjen Bebraud von Sprengitoffen. . . . . 271

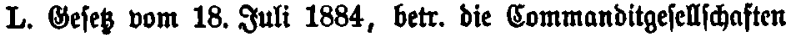

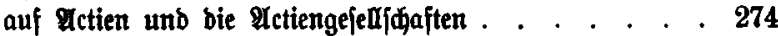

LI. Befeßs vom 24. Suni 1887, betr. bie Befteuerung des Brannt= weins . . . . . . . . . . . 275

\section{B. Landesseretęze.}

Preußen.

I. \$ireubifdeb \&anbredt . . . . . . . . . . . . . . . 276

II. 23 cgreglement bom 24. \$unt 1764 . . . . . . . . . . . . . 277

III. \$reupifide Apotbeterorbnung vom 11. October 1801; Circular= verfügung vom 11. Aluguft 1864. . . . . . . . . . . . 277

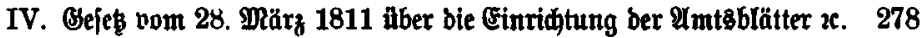

V. Brefeb wegent Entriatung Der Betwerbefteuer bom 30. Mai 18:20 mit Beję bom 3. Suli 1876 . . . . . . . . . . . 278

VI. B̈eję̧ wegen ber Stempelftener vom 7. Mär 1822 . . . . . 278

VII. Cabinet\$orbre vom 10. Sanuar 1824, bie Erbebung ber Maijळ= fteuer betr. . . . . . . . . . . . . . . . . . 279

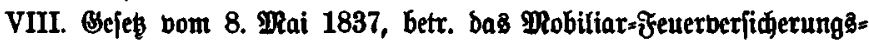
wojen . . . . . . . . . . . . . . . . . . . . 279

IX. Militär=Strafgeriđtzorbnung vow 3. April 1845 . . . . . 279

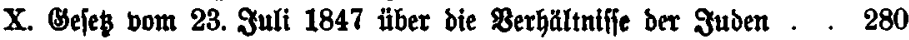

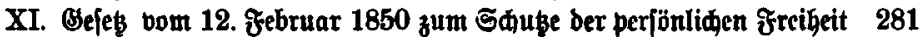

XII. Sagbpolizeigelę bom 7. $\mathfrak{T a ̈ r z}$

XIII. Berorbnung bom 11. März 1850 über baă Berjammlungăredt 281

XIV. Strafgefekbuđ bom 14, थpril 1851 . . . . . . . . . 282

XV. Mlaffenfteuergefes vom 1. MRai 1851 . . . . . . . . . . . 283

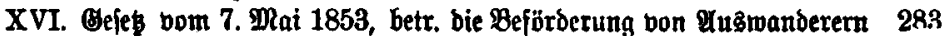

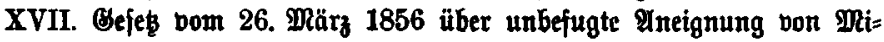
neralien . . . . . . . . . 283

XVIII. Berorbnungen bom 22. 3anuar 1867, bie Bcreibigung ber \$eamten zc. und bom 6. Mai 1867, bic ₹orm bcs Dienjteibes betr.

XIX. Befę bom 22. Zebruar 1867, betr. bie Befirajung ber unbefugten Aneignung bon Bernftein u. f. w. . . . . . . . . . 284 
XX. Berorbnung bom 25. Suni 1867, betr. bas Gtrafredt u. f. w. in ben 1866 mit ber Monarajie bereinigten Ranbestheilen . . 284

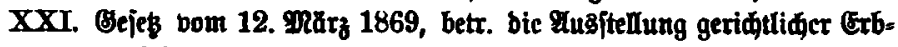
bejdeinigungen . . . . . . . . . . . . . . . . 284

XXII. Bormunbjđaft8orbmung bom 5. Juli 1875 . . . . . . . 285

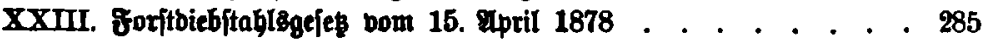

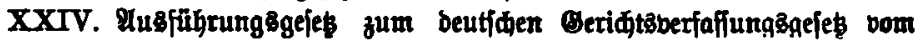
24. Wbril 1878 . . . . . . . . . . . . . . . 285

XXV. Felb unb Froritpolizeigeleb bom 1. April 1880 . . . . . . 286

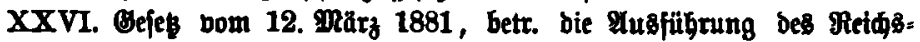

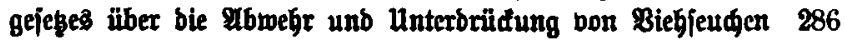

Elfá̧=Lothringen.

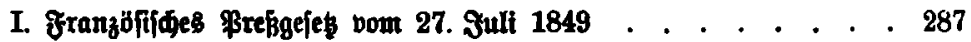

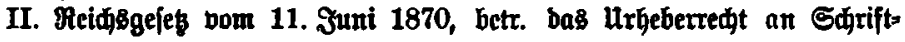

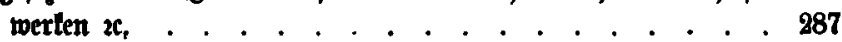

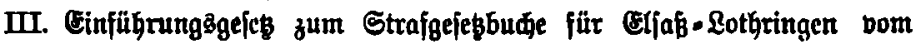
30. Uuguft 1871 . . . . . . . . . . . . . . . 288

Bayern.

I. Bolizeiftrafgejębuch vom 26. December 1871 . . . . . . . 288

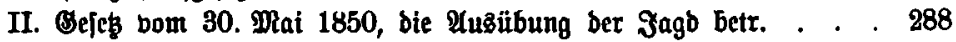

III. Forftgejes bom 28. Diai 1852 in ber Faffung ber Befanntmadung vom 26. September 1879 . . . . . . . . . . . . . . 289

IV. Malzaufialagegejeb vom 16. Mai 1868 . . . . . . . . . 289

V. Oeles bom 16. Mai 1868 , die Bermartung ber Brunbjtüafe betr. 290

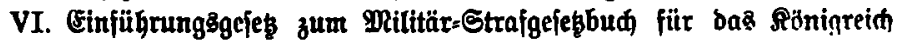
Bayern bom 29. 9pril 1869 . . . . . . . . . . . . . . 290

VII. Beję vom 10. $\mathfrak{M a ̆ r _ { z }} 1879$, betr. bie Befteuerung des Betwerbe betriebes im Umberzieben. . . . . . . . . . . . 290

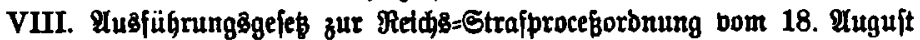
1879 . . . . . . . . . . . . . . . . . . . 290

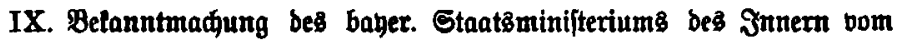
2. Samuar 1882, betr. bie Maßregeln gegen bie Minderpejt . 291

X. Beroronung bom 21. Iunt 1884, bie Berhăltniffe ber Baber betr. 291

XI. Befanntmađjung bes bayer. Staatominifteriums bes Snnern vom 22. Sanuar 1887, betr. bie Mafregeln gegen bie Minderpeft. 292

\section{Württemberg.}

I. Seję, betr. bie Cintommeniteuer oom 19. September 1852 . . . 292

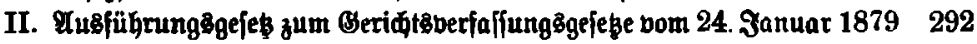

III. Forftftrafgejeß nom 2. September 1879 . . . . . . . . . . 292 


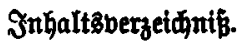

VII

\section{Baben.}

Geite

Sapitalrentenjteutergeję bou 29. Juni 1874 . . . . . . . . . . 293

\section{Medlenburg=のゅtoerin.}

Mebibirte Berorbnung, betr. Die Beftrafung ber \&elbfrebel, vom 2. Sep=

tember 1879 . . . . . . . . . . . . . . . . 293

Braunfqweig.

Sagbpolizeigcię bom 1. Ilprif 1879 . . . . . . . . . . . . . 293

Sahien= Sotha.

Branntweinfteuergefé vom 12. December 1833 . . . . . . . . . 293

Bremen.

Bormunbidaftânonung vom 14. Mai 1882 . . . . . . . . . . 294

Elplabetifdes Hegifter . . . . . . . . . . . . 295

Cgronologifdeg Regifter............... 461 
